\title{
CAMINHOS PARA \\ UMA ANÁLISE DISCURSIVA \\ DA VOZ NA DEFESA \\ DO TRIBUNAL DO JÚRI: \\ O EXCESSO, A FALTA, O \\ ESTRANHAMENTO
}

\section{CAMINOS HACIA UN ANÁLISIS DISCURSIVO DE LA VOZ EN DEFENSA DEL JURADO: EL EXCESO, LA FALTA, EL EXTRAÑAMIENTO}

PATHS TO A DISCURSIVE ANALYSIS OF THE VOICE IN THE DEFENSE OF THE JURY: THE EXCESS, THE LACK, THE STRANGENESS

Clóris Maria Freire Dorow*

Instituto Federal de Educação, Ciência e Tecnologia Sul-Rio-Grandense

\begin{abstract}
RESUMO: O referido artigo discute a questão da falta, do excesso e do estranhamento, tendo como materialidade discursiva o discurso jurídico da defesa em um tribunal do júri. A vertente teórica, que embasa esta discussão, é a Análise de Discurso francesa. No discurso jurídico escolhido, observou-se uma argumentação bastante articulada, na tentativa de tornar o discurso transparente e objetivo. Também puderam-se observar dois aspectos que sobressaem na argumentação: as formações imaginárias que tentam prever quem é o interlocutor e os esquecimentos número um e número dois que propiciam a ilusão de que o sujeito articula seu discurso de forma criativa e única, sendo que a grande meta do sujeito discursivo da defesa é destruir a argumentação de seu opositor. A partir dessas constatações, procurou-se então partir para a análise, e na escolha do corpus, foi essencial o aporte teórico trazido pelos aspectos abordados por Ernst, que constituem percursos eivados de perspectivas para o analista de discurso.

PALAVRAS-CHAVE: Falta. Excesso. Estranhamento. Voz.
\end{abstract}

RESUMEN: El artículo aborda el problema de la falta, del exceso y del extrañamiento, con la materialidad discursiva del discurso jurídico de defensa en un juicio con jurado. El modelo teórico que subyace en esta discusión es el análisis del discurso francés. En el discurso jurídico elegido, había un argumento muy articulado en un intento de hacer el discurso transparente y objetivo. También se podrían notar dos cosas que se interponen en el argumento: las formaciones imaginarias que tratan de predecir quién es la persona que llama y los olvidos número uno y el número dos que proporcionan la ilusión de que el sujeto articula su discurso de forma creativa y única, y el gran objetivo del sujeto discursivo de defensa es destruir los argumentos de su oponente. A partir de

\footnotetext{
* Doutora em Letras pela UCPel. Coordenadora do Curso de Pós-Graduação em Linguagens Verbo/Visuais e Tecnologias do Instituto Federal Sul-Rio-Grandense. Professora do Mestrado em Educaça do Instituto Federal SulRio-Grandense.E-mail:clorisdorow@hotmail.com
} 
estos resultados, partimos para el análisis, y los temas abordados por Ernst, que son caminos de trabajo para el analista, fueron esenciales considerando la elección del corpus.

PALABRAS CLAVE: Falta. Exceso. Extrañamiento. Voz.

ABSTRACT: The article discusses the issue of lack, excess and strangeness, with the discursive materiality of the legal discourse of the defense in a jury trial. The theoretical model that underlies this discussion is the French Discourse Analysis. In the chosen legal discourse there was a very articulate argument in an attempt to make the discourse transparent and objective. Wealso noticed two things that stand in the argument: the imaginary formations that try to predict who the caller is and the forgetfulness number one and number two, which provide the illusion that the subject articulates its creative and unique way of speech, and the great goal of the discursive subject of defense is to destroy the arguments of his opponent. From these findings we started our analysis, and Ernst's theoretical contribution, which presents possible paths for the discourse analyst, was essential considering the choice of the corpus.

KEYWORDS: Lack. Excess. Strangeness. Voice.

\section{INTRODUÇÃO}

Este artigo $^{1}$ tem como corpus o discurso jurídico da defesa em um tribunal do júri ${ }^{2}$, caracterizando uma argumentação que busca, enfaticamente, destruir o discurso da acusação, na tentativa de obter a absolvição da ré (crime acontecido na cidade de Pelotas, tendo como objetivo mostrar a inocência ou a culpa da acusada, que supostamente participou da trama para assassinar o próprio pai). Mesmo que os depoimentos e procedimentos apontem para a suposta participação da mesma em um crime, que acabou com a vida de seu progenitor, o advogado de defesa tem de apresentar uma argumentação convincente que possa redundar na absolvição da acusada.

\section{FALTA, EXCESSO E ESTRANHAMENTO NA ÓTICA DISCURSIVA}

O termo "argumentação" vem do latim argumentatio e é definido como o ato de apresentar ideias ou formular conceitos em prol de um objetivo. Argumenta-se para persuadir e, ao argumentar, o indivíduo pretende transmitir uma verdade aos ouvintes, buscando a concordância do outro. No tribunal do júri, a argumentação é a peça principal para a obtenção de um discurso vitorioso ou não. A fim de conseguir a atenção para o seu discurso e de aprimorar ainda mais a sua apresentação, a defesa busca fazer uma manifestação oral persuasiva, utilizando apelo emocional e recursos da retórica. Também é comum valerem-se de interpretações cênicas, com apelos teatrais e gestos eloquentes usados com diferentes entonações de voz, alongando as vogais de determinados vocábulos, questionando argumentos com ênfase e, ainda, usando o silêncio em momentos adequados.

$\mathrm{Na}$ argumentação, segundo Orlandi (2004, p. 61), “[...] todo o sujeito (orador) experimenta o lugar do ouvinte a partir de seu próprio lugar de orador, composto pelo jogo das formações imaginárias (a imagem que faz de x, de si mesmo, do outro)”. Essa concepção de antecipação, mais a de esquecimento, ligada ao interdiscurso, assim como de "formações imaginárias", tem uma importância capital, na medida em que os argumentos opostos, no discurso do tribunal de júri, são previstos normalmente antes da situação de enunciação, aí consideradas as posições de sujeito, a historicidade e as formações discursivas. Tal previsão, sobre como o outro vai reagir diante de determinadas argumentações, deve ser um dos fatores a ser considerado na elaboração de um discurso que pretende constituir-se em vencedor. Esse é um fator fundamental para a estratégia de preparação de um dizer, por vezes de teor duvidoso, que necessita ser entendido e aprovado por uma plateia heterogênea de jurados e que precisa destruir as argumentações do adversário, tornando-as sem efeito.

\footnotetext{
${ }^{1}$ Este artigo constitui-se em um recorte da minha tese de Doutorado intitulada "Mentira ou verdade? Marcas prosódicas assinalando sentidos no Discurso do tribunal do Júri”.

${ }^{2}$ Este júri aconteceu na cidade de Pelotas, em 2008, sendo a gravação feita pelo Promotor e emprestada à pesquisadora. O discurso analisado foi o da defesa. Maiores informações sobre o referido acontecimento não podem ser dadas por motivos éticos e legais, por isso os nomes utilizados são todos fictícios.
} 
Existe, segundo a autora, uma suposição do comportamento do ouvinte diante da argumentação, ou seja, como ele irá reagir diante dessa ou daquela palavra. É dessa forma que o sujeito locutor pensa como irá organizar os estratagemas que irão fundamentar o seu discurso. É pelo uso desse estratagema, de prever a reação e as argumentações contrárias que poderão ser suscitadas pelo opositor, que se encontra o funcionamento discursivo da argumentação. Para a autora, "Argumentar é prever, tomado pelo jogo de imagens. Quer se trate de transformar o ouvinte ou de identificar-se a ele, a antecipação joga a partir das diferentes instâncias dos processos discursivos" (ORLANDI, 2004, p. 76-77).

No discurso jurídico da defesa, tudo o que foi dito no júri ou em outros júris, além dos dizeres do senso comum e dos dizeres de outros discursos, está ali, significando, advindo do interdiscurso. Todos os sentidos já ditos, em inúmeros lugares e em momentos diversificados, mesmo longínquos, têm efeito sobre os dizeres. Por isso, para Pêcheux (1997), aquilo que se fala não constitui uma criação pessoal do falante, mas algo que já foi dito por alguém em algum lugar e em algum tempo, significando pela história e pela língua. Ao falar, o sujeito crê que tem plena ascendência sobre o seu dizer, mas, certamente, escapa-lhe a maneira como os sentidos funcionam no seu discurso:

Se uma mesma palavra, uma mesma expressão e uma mesma proposição podem receber sentidos diferentes [...] conforme se refiram a esta ou aquela formação discursiva, é porque [...] não têm um sentido que the seria "próprio" vinculado à sua literalidade. Ao contrário, seu sentido se constitui em cada formação discursiva, nas relações que tais palavras, expressões ou proposições mantêm com outras palavras, expressões e proposições da mesma formação discursiva (PÊCHEUX, 1997, p. 161, grifo do autor).

Há, assim, um elo entre o já-dito e aquilo que se fala, o mesmo que há entre o interdiscurso e o intradiscurso, isto é, entre a elaboração do significado e sua formulação. Orlandi (1999, p. 33) menciona que "todo dizer, na realidade, se encontra na confluência dos dois eixos: o da memória (constituição) e o da atualidade (formulação)". Segundo a autora, o interdiscurso é toda a gama de formulações elaboradas e já esquecidas que influenciam o que se fala. Desse modo, o interdiscurso tem por efeito fazer com que uma formulação dita anteriormente seja esquecida por completo, como se nunca antes fosse ouvida, passando, então, a tecer sentidos nas palavras pertencentes ao discurso.

De qualquer modo, o sujeito necessita, consciente ou inconscientemente, ignorar seu assujeitamento e, então, para ter a ilusão de ser o dono do seu discurso, conforme Pêcheux (1997), cria dois tipos de realidades discursivas ilusórias. Pêcheux (2001) explica essa questão por aquilo que ele chama de ilusões ou esquecimentos do sujeito. Para o autor, o sujeito é afetado por duas ilusões: o esquecimento $\mathrm{n}^{\circ} 1$, que é um ocultamento ideológico, um esquecimento através do qual uma sequência discursiva concreta é efetuada ou constatada como possuindo sentido - o que faz o sujeito conceber-se como a origem do seu dizer e o sentido como consequência desse seu dizer. O sujeito não percebe o pertencimento daquilo que diz a uma determinada formação discursiva e não a outra, uma vez que é interpelado pela ideologia; logo, a ilusão $n^{\circ} 1$ é inconsciente. Já o esquecimento $n^{\circ} 2$ direciona a crença do sujeito no sentido de presumir que aquilo que ele fala equivale ao que deduz sobre algo (transparência do pensamento), como se houvesse uma completa analogia entre a palavra e o mundo. É um ocultamento linguístico (pré-consciente/consciente), interligando-se à opção por uma determinada palavra e não por outra ao modo como inseri-la no discurso (paráfrase), isto é, selecionar uma forma, dentre as inúmeras concebíveis, de expressar a mesma coisa. Porém, o que não foi enunciado continua lá, pronto para ser transformado em dizer, acessível ao sujeito, que fez a escolha por determinado enunciado, a fim de compelir o interlocutor a entender de um modo e não de outro o discurso produzido, razão pela qual a ilusão n $n^{\circ} 2$ é préconsciente/consciente.

Contudo, tal esquecimento serve de sustentáculo aos sujeitos e aos sentidos, pois é através dele que o sujeito se ilude de ser o criador do seu dizer e de ser o produtor dos sentidos, ilusão essa que faz parte da constituição do sujeito. É desse modo que os vocábulos adquirem significados e os sujeitos significam, angariando dizeres já existentes como se fossem formulados no momento do seu discurso. As palavras são sempre as mesmas, porém seus significados estão sempre em mutação devido à história, à ideologia e ao contexto. E a argumentação é perpassada por todos esses fatores. 
Nessa contenda argumentativa, que se constitui em um verdadeiro embate, analisa-se alguns pontos de maior incidência no corpus. Dentre eles, destaca-se a questão da falta, do excesso e do estranhamento, que se constituem em sinais de alerta para o analista. Estes três aspectos, apontados por Ernst (2009), dentro de um determinado corpus, são, indubitavelmente, marcas indicativas para as quais o analista deve ficar atento.

Para Ernst (2009), uma das dificuldades do analista, diante do discurso a ser analisado, é como deve se feita a escolha do corpus discursivo, a fim de executar uma interpretação sob a ótica da Análise de Discurso. Assim, a opção por uma característica linguística ou enunciativa vai estar interligada ao modo de funcionamento do discurso sob a ótica do analista, "[...] aí implicados o sujeito submetido à ordem da ideologia e do inconsciente, a memória estruturante do dizer e o sentido opacificante" (ERNST, 2009, p. 01). A autora desenvolve o seu trabalho tomando como parâmetros três concepções, a saber, a falta, o excesso e o estranhamento. O analista, frente a um determinado discurso, vai observar se os enunciados possuem tais propriedades. Diz a autora (ibidem, p. 02) que, "numa dada conjuntura histórica frente a um dado acontecimento, aquilo que é dito demais, aquilo que é dito de menos e aquilo que parece não caber ser dito num dado discurso" pode constituir-se em pistas para dar início ao processo analítico.

No discurso que constitui o corpus deste artigo, pôde observar-se atentamente a concretização desses três aspectos nos recortes feitos. O excesso acontece quando determinados elementos se repetem de forma reiterada. Isso pode ser percebido, sobretudo, nos enunciados em que o advogado inocentava explicitamente a ré, usando expressões negativas, como "em nenhum lugar existe a prova”, "eu não vi a prova ou indício sequer de culpa", "ninguém disse que Dona Lara se apossou da empresa” e "não há nenhuma prova". Considerando o que diz Indursky (1990), a saber, que o "não" significa o "sim", essa incidência de expressões negativas parece denotar uma forma de convencimento não só dos jurados, mas da própria defesa em relação à culpabilidade da acusada.

O segundo aspecto mencionado por Ernst, a falta, pode acontecer no intradiscurso, quando determinados elementos ligados ao aspecto gramatical não acontecem, como a elipse e as reticências, sendo vistos dentro da $\mathrm{AD}$ como resultantes das determinações históricas do sujeito falante. Também a falta pode efetivar-se no interdiscurso de certa formação discursiva, "que só poderá ser resgatado a partir do apelo aos exteriores da linguística, provocando um contingenciamento discursivo. Isso se estabelece em função de determinadas condições de produção históricas e/ou enunciativas” (ERNST, 2009, p. 04).

A fim de explicitar o terceiro aspecto mencionado pela autora, o estranhamento, recorre-se aqui a um exemplo extraído do corpus, quando a defesa fala: "A jaqueta... Não sei como ela entrou no libelo acusatório... Usar a jaqueta do marido é uma prova? Esperavam que ela viesse pressionada pelo peso desses volumes... Então ela estaria flutuando... pois aqui não há pesos... não há...”. Esses são enunciados que se reportam a colocações da acusação e que são ditos em um contexto posterior, o que denota um estranhamento. Aquele que não prestou atenção no que a acusação argumentou, no dia anterior, em relação a esses aspectos, acaba não entendendo tais ideias. Nesse caso, seria a pressão da culpa, argumentada pela acusação, dizendo que a ré deveria estar vergada pelo peso de sua culpa, e não fria, sem expressar nenhuma emoção.

Também esse terceiro aspecto pode efetivar-se quando há uma estratégia discursiva que expõe o conflito entre formações discursivas que se tornam presentes no intradiscurso e que se mostram através do pré-construído. Para Ernst (2009, p.5), o estranhamento "[...] possui como características a imprevisibilidade, a inadequação e o distanciamento daquilo que é esperado" . Outro exemplo de estranhamento no corpus é observado em "Em nenhum lugar existe a prova de que Dona Lara planejou e participou do crime, a não ser nos pensamentos dispersos pelo tempo". Nesse exemplo, o estranhamento acontece porque, num discurso de defesa de não participação da ré no planejamento do crime, surge uma formação discursiva poética, pouco provável de aparecer em um discurso do tribunal do júri que tenta expressar-se através de uma linguagem objetiva.

Percebe-se, então, o quanto é importante, no recorte do corpus, o analista atentar para esses três aspectos mencionados por Ernst (2009), os quais se tornam um parâmetro bastante seguro na escolha dos enunciados que serão submetidos à análise. Logo, através dos critérios de escolha do corpus discursivo mostrados pela autora, torna-se bem mais fácil ter alternativas fundamentadas nas opções de recorte do discurso da defesa. Nas sequências discursivas analisadas consideram-se as maneiras como os sentidos são linearizados, as formações discursivas de onde provêm e as diferentes posições discursivas que emergem no discurso da defesa. 


\section{ANÁLISES}

SD1 - Jurados de minha terra, dessa terra que marcou a história brasileira porque aqui se aboliu a escravatura, aqui se deu início à luta pela liberdade... Aqui nunca se permitiu que a liberdade, de quem quer que seja, fosse traída, fosse massacrada, e vós, a sociedade de Pelotas, que aqui está, com o supremo direito de julgar, direito de decidir sobre a liberdade de uma pessoa, não ireis permitir que isso aconteça.

No caso do discurso jurídico analisado, o sujeito necessita combater os argumentos de seu opositor, precisa colocar-se no lugar do outro através da antecipação, e necessita, também, estar na posição enunciativa que lhe cabe. O sujeito que aí se pronuncia é a defesa, manifestando, em seu discurso, o que constitui dever de seu lugar social empírico: tentar evidenciar a inocência ou a menor gravidade do ato cometido por sua cliente. Nos momentos em que se manifesta dentro do processo, há, igualmente, a voz e o desejo da cliente que está representando. Assim, a defesa fala na posição de porta voz da acusada, expressando palavras que buscam convencer os jurados de que a imagem delineada pela Promotoria é equivocada: a ré não é a figura malévola que foi apresentada, ela é aquela que está sendo julgada injustamente, ela é o Bem e não o Mal.

No dizer de Krüger (1997), verifica-se que jamais alguém mente sem ter a noção de que está escondendo a "verdade", pois mentir não é asseverar algo falso, mas, sim, afirmar algo que se admite ser falso. Isso porque não há mentira desprovida de intenção; há sempre motivos, causas, razões e intenções. Nesse sentido, "[...] a mentira, como substituto da compensação, atenua a insatisfação humana e compensa nossa condição trágica de sempre desejar e sonhar com mais do que podemos ter” (KRÜGER, 1997, p. 24). Nesse caso específico da defesa, existe a intenção clara de defender a ré e de, principalmente, tornar o seu discurso o vencedor, afinal o júri é uma contenda. A defesa assim “construiu” sua argumentação, embasada no preceito de provar a inocência da ré.

Ao argumentar, segundo Orlandi (1998), as filiações ideológicas encontram-se já articuladas, e as alternativas da argumentação apenas lhe propiciam sentido. O sujeito já possui uma posição pronta, ainda que a argumentação seja articulada pelas intenções do mesmo, gerando seus argumentos à mercê de sua ilusão subjetiva "[...] afetada pela vontade da verdade, pelas evidências do sentido. Os próprios argumentos são produtos dos discursos vigentes, historicamente determinado” (ORLANDI, 1998, p. 06).

Na primeira parte do discurso, aqui em foco, a defesa faz um chamamento através do vocativo "Jurados da minha terra", trabalhando com a ideia de que nesta terra, Pelotas, historicamente se lutou pela liberdade desde a abolição da escravatura. Coloca ênfase na palavra "aqui", destacando o fato de ser Pelotas uma cidade com ideais de liberdade, postos em prática no decorrer do tempo, como o atestam os acontecimentos. Sendo o lugar onde acontece o julgamento da ré, tal como em outros momentos da história, o seu ideal de liberdade não pode ser comprometido, tampouco destroçado. A defesa dirige-se, então, diretamente aos jurados, convocando-os a partilhar os ideais de liberdade, pois a eles foi dada a responsabilidade de sentenciar o destino de alguém que está sendo injustiçado e que merece obter uma sentença justa: a absolvição.

A história narrada serve para reavivar um fato que está na memória do sujeito como um fato histórico; é um já-dito que precisa ser relembrado e repetido, como confirma o uso dos tempos e dos modos verbais. O tempo pretérito perfeito é usado como forma de mostrar um fato que realmente aconteceu, "marcou", "aboliu", "deu início", "nunca se permitiu" e que precisa acontecer de novo. O passado, pois, necessita ser seguido no presente para fazer jus a uma tradição. A sequência "vós, a sociedade de Pelotas, que aqui está" é uma forma de relembrar aos jurados o que eles representam no júri, o povo da cidade, precisando honrar essa representação. Ao dizer "não irão permitir que isso aconteça", o advogado complementa seu discurso, usando o verbo no futuro do presente do indicativo, no mesmo modo dos demais, o modo que, como se sabe, representa a certeza.

Utilizando-se dos enunciados com formações discursivas históricas como argumentos para o seu discurso, a defesa imprime sentidos cristalizados, a fim de direcionar significações, buscando evitar contradições e colocando em prática a ideologia jurídica, que possui cerceamentos e leis definidas. Formações discursivas que se opõem mostram-se no discurso do porta-voz. 
É importante fundamentar o sentido trazido pela rememoração de um fato histórico. Para Pesavento (2007), história e memória comungam semelhante modo de existir, sendo as duas narrativas formas de exprimir o mundo, de mirar o real. São enunciados que expressam, narram, descrevem, explicitam e legam sentidos a um fato, a uma realidade.

Fica evidenciado que a repetição da palavra "aqui" emerge no discurso da defesa como uma forma de mostrar que neste lugar, nesta cidade, a justiça é sempre feita e esse fato não pode ser ignorado no caso da ré que, na argumentação da defesa deve ser inocentada. Assim como as narrativas sobre alguma coisa, elas são reproduções de algo, ou seja, "são discursos que se colocam no lugar da coisa acontecida" (Pesavento, 2007, p.27) Mais do que isto, história e memória são discursos portadores de imagens, que dão a ver aquilo que dizem através da escrita ou da fala; são ambos “presentificação de uma ausência” (idem, p. 37). Nesse caso, é a presentificação de uma ausência que precisa ser lembrada para ser seguida pelos sujeitos jurados.

\section{SD2 - O casaco, que importância teria? Foi apenas uma troca... é motivo para acusação tão forte? Por quêe? É por falta de motivos? Talvez... o que o Promotor procura? Culpas...? Que culpas...? Têm culpas...?}

Nesta sequência discursiva percebe-se dois fatores apontados por Ernst (2009): a falta e a repetição. A falta acontece porque o sujeito discursivo da defesa não retoma o fato explicitado pela promotoria, resgatando apenas algumas palavras que aparecem de maneira desconectada, com reticências e interrogações. Anteriormente, o sujeito discursivo da promotoria já havia abordado, no início do seu dizer, a questão de um casaco que a ré havia trocado com o marido, também acusado de participação no crime. Essa jaqueta o identificava, em mais de uma ocasião, nos momentos em que se encontrou com o executor do assassinato, assim como confirmava sua presença no local onde o corpo havia sido enterrado. Essa troca, realizada pela acusada, foi enfatizada várias vezes pelo sujeito discursivo da promotoria como uma forma de mostrar que a acusada era coautora do crime, pois estaria protegendo seu consorte.

Em contrapartida, na metade de seu discurso, como uma forma de destruir argumentos da acusação, a defesa aborda o assunto sem retomar o discurso do adversário, ficando um dizer desconectado, onde falta uma ligação com os fatos já abordados no discurso da Promotoria. Analisando este dizer, percebe-se que parecem faltar argumentos para o advogado e ele faz essa digressão meio solta, repetindo as palavras como "motivo" e "culpa" que foram as duas palavras mais utilizadas pelo sujeito discursivo da promotoria. Nas pausas de seu dizer, mostradas pelas reticências, percebe-se que faltam argumentos ou que argumentos estão deixando de ser ditos, pois piorariam a situação da ré. Para Orlandi (2001, p.121), o silêncio contém o mais importante, o que se deixou de dizer e que não pode ou não deve emergir no discurso. Complementa dizendo que "[...] as reticências são signos de silêncio, presença de uma ausência anunciada. Um acréscimo radical que abre para tudo, para qualquer coisa. Não é o vazio: elas marcam o lugar de um acréscimo possível". Portanto, o uso de tal tipo de pontuação significa um dizer que não se presentifica através da palavra, mas da simbolização dos três pontos que se revelam detentores de muitos dizeres.

Retomando a questão da repetição, sob a ótica da Psicanálise, pode-se constatar que, para Lacan (1998), a repetição é vista, inicialmente, como obstáculo, e num segundo momento, como acontecimento. É assim que o autor representa a segmentação entre a repetição imaginária (ligada à fantasia), simbólica (automatismo da cadeia significante) e real. Se as duas primeiras podem ser concebidas como retorno, a última será visualizada de outra forma, ao ser associada a lacunas que se mostrariam na significação, pontos irredutíveis de resistência à simbolização. Nesse sentido, a repetição real, para além da reaparição de conteúdos recalcados ou de efeitos da cadeia significante, traz à tona a insistência daquilo que não pode ser absorvido enquanto sentido. Entre essa visão de Lacan sobre a repetição e o que foi dito sobre a falta nessa sequência discursiva do corpus, pode-se fazer um paralelo com a ideia de lacunas que assomariam nos sentidos, por uma falta de dizer que se recusa a ser simbolizado ou um dizer que não pode ser simbolizado porque acarretaria danos à defesa da ré.

Também, pode-se observar que, além das reticências já comentadas, há uma outra forma de pontuação que se repete: as interrogações, emergindo em uma sequência discursiva relativamente pequena, indicando que são questionamentos os quais o próprio sujeito discursivo não pode responder e surgem ali, de forma reiterada, direcionadas para os sujeitos ouvintes para suscitar dúvidas em relação aos fatos, assim como indagações cujas respostas não foram dadas pela defesa e, sim, pela promotoria, que precisava ser desacreditada. Dessa forma, o silêncio e as interrogações são usados, vindos do interdiscurso, como forma de 
proteção para um dizer que não deve ser simbolizado, sob pena de destruir argumentos de um discurso aparentemente planejado pelo sujeito discursivo da defesa, que poderá ser destruído por argumentos contraditórios. Para o jurídico, o silêncio não significa, a palavra não dita não é registrada nos autos, mas os sentidos não deixam de significar, apesar da tentativa de torná-los transparentes.

\section{SD3 - Nada tem a ver com o planejamento que era o motivo do libelo acusatório. Nada tem a ver com a contratação de cadáver, isto é, a contratação para enterrar o cadáver. Quem diz o que quer, ouve o que não quer. Mas a justiça está sempre atenta em relação à verdade, ela pune os que não a cumprem...}

Além do excesso de expressões negativas, essa sequência apresenta estranhamentos. Um deles está relacionado à ligação entre os enunciados que parecem estar desconectados, embora seja possível, ao ouvinte, estabelecer os nexos a partir de ligações com outros eventos do júri, como as colocações feitas pelo discurso da promotoria, a qual fez acusações veementes relativas à participação da acusada no crime. Além disso, nesse enunciado, aparecem atos falhos que expressam estranhamentos, advindos do inconsciente, e indicam verdades submersas que se entremostram. Foi a partir da psicanálise que houve a descoberta dos atos falhos. Assim, para aqueles que desconhecem a psicanálise e querem ocultar o real sentido dos supostos erros, os atos falhos são considerados simples erros/trocadilhos, um ocorrido "sem querer", que não têm a maior importância, que não possuem nenhuma causa e que recebem a denominação de "equívoco". Freud (2006) explicitou esses supostos erros/tropeços como tendo um sentido oculto que necessita ser desvelado. Assim, os atos falhos consistem em pequenos lapsos - esquecimentos de nomes, horários, datas, coisas a fazer, ou algo dito - que emergem de forma inesperada, ou seja, todo processo em que ocorre alguma interferência no que foi planejado, na atitude "normal" esperada, causando estranhamento. Para Lacan (1986, p. 302), "nossos atos falhos são atos que são bem sucedidos, nossas palavras que tropeçam são palavras que confessam. Eles revelam uma verdade por detrás. [...] Se a descoberta de Freud tem um sentido é este - a verdade pega o erro pelo cangote, na equivocação”.

Para Pêcheux (1997), é através da palavra que o sujeito desvela sua ideologia. Assim, no discurso da defensoria, ocorrem dois atos falhos: um, ao dizer "contratação do cadáver", em vez de "contratação do pistoleiro"; e outro, na correção do enunciado “contratação para enterrar o cadáver", em vez de "contratação para o assassinato”. O mais estranho é que, à época do júri, o assassino já havia sido executado, após ameaçar contar toda a verdade. Então, foi a contratação de alguém que seria executado que se transformou em um cadáver. A palavra volta a aparecer, mesmo o advogado corrigindo o ato falho. O combinado era que o assassino enterrasse a vítima em um lugar inusitado e bem fundo, para que o cadáver não fosse descoberto, e não foi isso que aconteceu, pois o corpo da vítima acabou sendo encontrado. Assim, o sujeito fala e, ilusoriamente, tem a certeza de que tem conhecimento sobre o que expressou em palavras, porém ele não tem como dominar a maneira pela qual os sentidos se estabelecem.

Nesse enunciado com tantas negativas, é importante trazer o pensamento de Indursky (1990). A autora caracteriza o sentido de negação como a denegação da psicanálise, trazendo-a para o âmbito da Análise de Discurso e denominando-a 'denegação discursiva'. Indursky a define como aquela negação que, por recair em um vocábulo, exprime um saber próprio à FD, trazendo consequências para o sujeito do discurso. Isto é, a denegação discursiva estabelece elos com o domínio da FD e com o sujeito que interage com ela. Logo, seu resultado não é controverso, não é polêmico.

Existe um fator que é repudiado pelo sujeito do discurso, mas que, ao mesmo tempo, pode ser enunciado por este mesmo sujeito. Tal fator, portanto, encontra-se recalcado na FD, aparecendo no discurso somente através de uma negação (INDURSKY, 1990, p. 120). Na denegação discursiva, o "não" encobre um "sim”. É o que parece ocorrer no discurso da defesa que usa, em vários momentos, expressões negativas, de maneira que esse uso repetido faz com que o analista do discurso perceba um outro sentido, aflorado pela negativa: "Ela não tem culpa" metamorfoseia-se em "Ela tem culpa". Assim, o que está significando no dizer da defesa, mesmo negando, é: "Tudo tem a ver com o planejamento. Tudo tem a ver com a contratação do cadáver....", pois, em todo o discurso no qual a negação se faz presente, existe uma afirmação no interdiscurso que aflora. 
Mesclam-se, nesse discurso, a negação da culpa da ré, opondo-se com veemência ao argumento da acusação, uma formação discursiva de um dito do senso comum "Quem diz o que quer, ouve o que não quer" e um dizer advindo da formação discursiva jurídica, propalando uma defesa acirrada do quanto a justiça é verdadeira e atenta. Com isso, a defesa pretende mostrar aos jurados que é no seu discurso que se encontra a "verdade”, e não no discurso do adversário.

\section{CONCLUSÃO}

Dentre as inúmeras opções propiciadas pelo corpus selecionado, teria sido bastante difícil fazer uma escolha dos recortes, diante de um discurso rico em caminhos para análises profícuas e com aspectos discursivos instigantes, dentre eles, as formações discursivas que desvelam a ideologia propagada pelo sujeito discursivo da defesa. Mas, indubitavelmente, foi o uso dos três fatores a falta, o excesso e o estranhamento, apontados por Ernst (2009), os indicadores de opções que concretizaram análises deveras interessantes, embasando a fundamentação teórica explicitada anteriormente e objetivando uma boa análise.

No discurso que constitui o corpus deste artigo, pôde-se observar a concretização desses três aspectos mencionados. O excesso se efetiva quando certas palavras ou expressões e elementos da memória são reincidentes no discurso. Já o segundo aspecto, relativo à falta, efetua-se no intradiscurso, quando elementos gramaticais ou interdiscursivos são esperados, mas não acontecem. Como exemplo de falta de elementos gramaticais, têm-se a elipse e as reticências, elementos esses considerados na AD como resultantes das determinações históricas do sujeito falante. O terceiro aspecto, o estranhamento, pode ser explicado como uma estratégia discursiva que expõe o conflito entre formações discursivas presentes no intradiscurso e que se evidenciam por meio do préconstruído.

Logo, no percurso empreendido, o que se pôde perceber, principalmente, é que o excesso de negativas demonstra que, por detrás do dito, existe um não dito significando. Provavelmente, isso encaminhe para a conclusão de que alguma FD foi dissimuladamente mobilizada pelo sujeito discursivo da defesa como parte de outra FD constitutiva do seu dizer, a fim de convencer e de mostrar uma "verdade". Além disso, a falta e o estranhamento concretizaram-se em alguns enunciados do corpus, funcionando como balizadores de novos sentidos que propiciaram análises muito bem fundamentadas. Sobre esses artifícios discursivos, presentes no tribunal de júri, o presente trabalho se dedicou a refletir, na tentativa de chegar aos efeitos de sentido daí decorrentes.

\section{REFERÊNCIAS}

ERNST, A. G. A falta, o excesso e o estranhamento na constituição/interpretação do corpus discursivo. In: SEMINÁRIO DE ESTUdOS EM ANÁLISE DO DISCURSO, 4., 2009, Porto Alegre, RS. Anais... Porto Alegre: UFRGS, 2009. Disponível em: <http://anaisdosead.com.br/4SEAD/SIMPOSIOS/AracyErnstPereira.pdf>. Acesso em: 15 dez. 2015.

FREUD, S. A mentira. Obras completas. v.3. São Paulo: Imago, 2006.

A Negativa. Obras completas. São Paulo: Imago, 1996.

INDURSKY, F. Polêmica e denegação: dois funcionamentos discursivos da negação. Cadernos de Estudos Linguísticos, Campinas, v.19, p.117-122, 1990 .

JÚRI popular. [Pelotas, 2008].

LACAN, J. O seminário, livro 11, Os quatro conceitos fundamentais da psicanálise. Rio de Janeiro: Jorge Zahar, 1988. 
KRÜGER, I. Da impossibilidade de viver sem mentir. São Paulo: Pensamento, 1997.

ORLANDI, E. Análise de discurso. Campinas, SP: Pontes, 1999.

. Discurso e Argumentação: um observatório do político. Fórum Linguístico, Florianópolis, n. 1, p.73-81, jul./-dez. 1998.

. Interpretação - autoria, leitura e efeitos do trabalho simbólico. Campinas, SP: Pontes, 2004.

. Discurso e texto: formulação e circulação dos sentidos. Campinas, SP: Pontes, 2001.

PÊCHEUX, M. Semântica e discurso. Campinas: Pontes: 1997.

Análise automática do discurso (AAD-69). In: GADET, F.; HAK, T. Por uma análise automática do discurso. Uma introdução à obra de Michel Pêcheux. Campinas: Ed. UNICAMP, 2001. p.59-158.

PESAVENTO, S. Palavras para crer: imaginários de sentido que falam do passado. In: INDURSKI, F.; FERREIRA, M.C. Análise do discurso no Brasil. São Carlos: Clara Luz, 2007.p.37-46. 